\title{
Impact of a psychiatry clerkship on stigma, attitudes towards psychiatry, and psychiatry as a career choice
}

\author{
Zaza Lyons ${ }^{*}$ and Aleksandar Janca
}

\begin{abstract}
Background: Mental illnesses are a major public health problem around the world and the prevalence and burden of common mental disorders is growing. Psychiatry is an unpopular career choice for many medical students and this impacts negatively on the supply of psychiatrists to the workforce. The psychiatry clerkship can play an important role in influencing students' attitudes towards psychiatry, either positively or negatively. However, stigma towards mental illness detracts students from considering a career in psychiatry. The aim of this study was to assess the impact of an eight week psychiatry clerkship on i) student knowledge and interest in psychiatry; ii) psychiatry as a career choice; iii) attitudes towards psychiatry; and iv) perceptions of stigma towards mental illness.
\end{abstract}

Method: Year 4 medical students at the University of Western Australia completed two questionnaires, the Balon Attitudes Towards Psychiatry and the Mental IIIness Clinicians Attitudes (MICA), at the beginning and end of the psychiatry clerkship. Interest in, knowledge of, and consideration of psychiatry as a career were also assessed. Non-parametric tests were used to compare baseline and follow-up differences on the Balon and MICA. Unpaired t-tests compared mean differences for interest, knowledge and psychiatry as a career.

Results: Attitudes towards psychiatry were positive at the beginning of the clerkship. Overall, there was a significant decrease in negative and stigmatising views towards mental illness post clerkship measured by the MICA, but the follow-up mean score remained close to the neutral value with views in some areas becoming more negative. There was no significant improvement in students' interest in psychiatry post clerkship, however, knowledge of psychiatry improved significantly. Numbers of students 'definitely considering' psychiatry as a career increased significantly from 7 (4.6\%) students at baseline to 17 (10.5\%) at follow-up.

Conclusion: The clerkship made a modest impact on students' attitudes to psychiatry, stigma and consideration of psychiatry as a career. Integration of strategies to overcome stigma towards mental illness and the mental health profession into pre-clinical teaching may provide students with skills to prepare them for the clerkship. This may assist in improving attitudes towards psychiatry and encourage more students towards a psychiatry career.

Keywords: Medical students, Stigma, Career, Attitudes, Psychiatry, Clerkship

\section{Background}

Mental illnesses are a major public health problem around the world [1]. They are common, disabling and debilitating conditions [2] that impact negatively on a person's quality of life, their ability to lead productive and fulfilling lives and form meaningful family, social

\footnotetext{
*Correspondence: zaza.lyons@uwa.edu.au

School of Psychiatry and Clinical Neurosciences, M521, The University of Western Australia, 35 Stirling Highway, Crawley, Perth 6009, Western Australia, Australia
}

(c) 2015 Lyons and Janca; licensee BioMed Central. This is an Open Access article distributed under the terms of the Creative Commons Attribution License (http://creativecommons.org/licenses/by/4.0), which permits unrestricted use, distribution, and reproduction in any medium, provided the original work is properly credited. The Creative Commons Public Domain Dedication waiver (http://creativecommons.org/publicdomain/zero/1.0/) applies to the data made available in this article, unless otherwise stated. and personal relationships [3]. Furthermore, people with mental illness are among the most stigmatised, marginalised and vulnerable members of society and suffer from discrimination in many areas of daily life as a consequence of their illness [4]. The prevalence and incidence of common mental disorders are predicted to rise in the coming decades. In particular, age related conditions including dementia will increase and add significantly to the overall global burden of disease caused by mental illness $[5,6]$. 
In order to ensure that the psychiatric workforce remains sustainable into the future, new generations of motivated and enthusiastic young doctors need to be encouraged towards a career in psychiatry. However, a recent systematic review concluded that while medical students attitudes towards psychiatry are generally positive, psychiatry as a potential career choice is unpopular [7]. A comprehensive international survey of medical students in 20 countries found that overall, only $4.5 \%$ of students were 'definitely considering' psychiatry as a career [8]. As a result of this ambivalence towards psychiatry, recruitment to postgraduate psychiatry training has been consistently low for decades. Analysis of the career choices of newly qualified doctors in the UK found that from 1974 to 2009 psychiatry was the first career choice for around $3-5 \%$ of medical graduates per year [9] and similar trends have been reported in other countries [10]. In its 2012 report, Health Workforce Australia reported a current shortage of psychiatrists, and estimated that by 2025 this would worsen significantly and result in a shortage of up to 452 psychiatrists, one of the highest levels of shortage across all areas of medical specialisation [11].

Stigma towards mental illness has increasingly been identified as a factor that influences medical student attitudes towards psychiatry and detracts them from considering psychiatry as a career [12-14]. Medical students often have stigmatised views towards mental illness prior to commencement of their medical training $[15,16]$. Negative views can be further strengthened when students start clinical clerkships in psychiatry and have contact with mentally ill patients [12,17]. Clerkship studies have found that students feel uncomfortable with patients [18], feel that mentally ill patients have a poor prognosis [19] and that interacting with patients is stressful [20]. In other studies, students have reported that working with patients is dangerous [21], disturbing, emotionally draining and overwhelming $[15,22]$.

Medical students considering psychiatry as a career will often be subject to stigmatising comments regarding their choice from others, including family members and friends $[15,23]$, further alienating them from psychiatry as a career. For psychiatrists, stigma often persists throughout their career [10] with the profession perceived as having a negative image, both in the community and by other medical specialists $[24,25]$.

Clerkships (also called attachments, placements or rotations) form a core component of clinical teaching in medical schools. Psychiatry clerkships are often the first exposure that students have to patients with mental illness, psychiatric wards and mental health services more generally. A U.S. study found that the length of the psychiatry clerkship varied between medical schools ranging from 4-8 weeks, averaging around 6.2 weeks [26].
A systematic review of the impact of the psychiatry clerkship that assessed 26 studies from 19 countries found that the average length of clerkship was 5.5 weeks with 4 weeks the most common length [27]. Clerkships provide a good opportunity for academics and others involved in clinical teaching to promote psychiatry to students, including its career potential. However, while they have a positive effect on students attitudes towards psychiatry, there is mixed evidence of their impact on psychiatry as a career choice [27].

In order to investigate this apparent disparity between positive attitudes towards psychiatry as a discipline and negative attitudes towards psychiatry as a career, and explore the role that stigma may play, a survey of medical students was undertaken. The aim of the study was to assess the impact of the eight week clinical clerkship in psychiatry on i) student knowledge and interest in psychiatry; ii) psychiatry as a career choice; iii) attitudes towards psychiatry; and iv) perceptions of stigma towards mental illness.

This paper will report on the results of this study and discuss strategies that may assist to improve students attitudes towards mental illness and psychiatry as a career choice.

\section{Method}

\section{The psychiatry clerkship}

The current medical course at the University of Western Australia (UWA) is a six year undergraduate Bachelor of Medicine, Bachelor of Surgery (MBBS) degree. During Year 4 students rotate through four different eight week clinical clerkships, including psychiatry, in groups of approximately 60 . These clerkships are the first opportunity that students have to experience working in hospitals and other clinical settings. For the psychiatry clerkship students are divided into smaller groups of 4-8 and allocated to a clinical teaching site that is attached to a psychiatric inpatient unit. During the eight weeks they have several additional shorter visits to old-age and alcohol and drug rehabilitation services. As well as ward work with a clinical team including consultants and registrars, students also have a three hour tutorial per week which is facilitated by an academic staff member and covers theoretical components of psychiatry. These tutorials cover a range of case based learning scenarios including mood disorders, anxiety disorders, schizophrenia, substance abuse, personality disorders and organic disorders. A two day introductory course of lectures is given at the beginning of the clerkship. The main component of assessment is a case presentation where students are required to interview a patient for an hour followed by a presentation of the findings and discussion with the examiner.

\section{Study design and procedures}

Study participants were Year 4 MBBS medical students at UWA who were undertaking their eight week 
psychiatry clerkship. Students were asked to complete two questionnaires on the first day of the clerkship (baseline) and again towards the end of the clerkship (follow-up). Questionnaires were distributed during tutorial contact time and participation was voluntary. To ensure confidentiality no identifying information was collected.

Ethics approval for the study was granted from the UWA Human Research Ethics Committee. Consent to participate in the survey was implied if students decided to complete the survey.

The Balon Attitudes Towards Psychiatry questionnaire [14] and the Mental Illness Clinicians Attitudes Scale (MICA) (medical student version) [28] were used in the study. The Balon questionnaire was developed in 1999 and has been used in a number of studies that have been conducted in different countries to measure medical students attitudes toward psychiatry. It has 29 items and is rated on a 4 point scale - strongly agree, moderately agree, moderately disagree, strongly disagree. The following themes are covered: i) overall merits of psychiatry; ii) efficacy; iii) role definition and functioning of psychiatrists; iv) possible abuse and social criticism; v) career and personal reward; and vi) specific medical school factors.

The medical student version of the MICA was developed and validated in 2010 [28]. It has 16 items and is rated on a 6 point Likert scale - strongly agree, agree, somewhat agree, somewhat disagree, disagree, strongly disagree. The minimum total score is 16 , maximum 96 . A lower score indicates a less stigmatising attitude towards mental illness and psychiatry.

In addition to the Balon and MICA, demographic data was collected. Students were also asked to rate their interest in, and knowledge of psychiatry on a 10 point visual analogue scale $(1=$ low interest $/$ knowledge; $10=$ high interest/knowledge) and their extent of consideration of psychiatry as a career on a 10 point scale $(1=$ definitely not considering; 10 = definitely considering).

Statistical analyses were carried out using IBM SPSS software, Version 22.0. Unpaired t-tests were used to compare mean differences on the visual analogue scale questions. Non-parametric tests were used to compare baseline and follow-up differences on Balon and MICA items. As the full range of responses on the 4 point Balon rating scale had not been utilised by many respondents on a number of the questions, the rating scale was dichotomised into 'agree' and disagree' variables and the percentage agreement/disagreement for each item was calculated. McNemars test was used to determine significance between baseline and follow-up on each item. For the MICA, the negatively worded questions were reverse scored and the mean total baseline and post scores calculated. An unpaired t-test was used to determine statistical significance on the mean scores, a Mann-Whitney test tested differences between male and female students and a Wilcoxon signed rank test determined any significant changes between baseline and follow-up on each item. The significance level for all statistical testing was set as $\mathrm{p}=<0.05$.

\section{Results}

Approximately 238 students were invited to participate in the baseline survey, and 230 to the follow-up survey. One hundred and fifty one students responded to the baseline survey (63\% response rate), and 161 responded to the follow-up survey ( $70 \%$ response rate). At baseline, $68(45 \%)$ respondents were male and 83 (55\%) female. At follow-up 77 (48\%) were male and 84 (52\%) female. The mean age was 23 years, range $20-40$ years.

\section{Interest, knowledge and psychiatry as a career}

The baseline means for interest and knowledge of psychiatry, and psychiatry as a career were 5.7/10, 3.5/10, and $3.9 / 10$ respectively. The follow-up means for interest and knowledge of psychiatry, and psychiatry as a career were 6.1/10, 6.0/10, and 4.8/10 respectively. An unpaired t-test found that there were no significant changes at follow-up on the level of interest in psychiatry $t(310)=$ $1.6133, p=0.1077$. There was, however, a significant improvement on the level of knowledge of psychiatry, and interest in psychiatry as a career, $\mathrm{t}(310)=15.4053, \mathrm{p}=$ 0.0001 and $\mathrm{t}(310)=3.3804, \mathrm{p}=0.0008$ respectively. Details are shown in Table 1.

Mann-Whitney U tests found that they were no significant differences between male and female students at either baseline or follow-up in interest in psychiatry (baseline $\mathrm{p}=$ 0.123 ; follow-up $\mathrm{p}=0.394$ ), knowledge of psychiatry (baseline $\mathrm{p}=0.240$; follow-up $\mathrm{p}=0.663$ ) or psychiatry as a career (baseline $\mathrm{p}=0.756$; follow-up $\mathrm{p}=0.451$ ).

The number of students definitely considering a career in psychiatry (those who scored the question as 8,9 , or 10/10) rose from $7(4.6 \%)$ students at baseline to 17 (10.5\%) at follow-up.

\section{Attitudes towards psychiatry}

Overall, students reported positive attitudes towards psychiatry, both at baseline and follow-up. Only three Balon items showed a statistically significant change post clerkship, all of which were in the positive direction.

Table 1 Changes in interest, knowledge and psychiatry as a career

\begin{tabular}{lllll}
\hline & $\begin{array}{l}\text { Baseline } \\
\text { mean (sd) })\end{array}$ & $\begin{array}{l}\text { Follow-up } \\
\text { mean (sd) }\end{array}$ & $\boldsymbol{t}$ & p value \\
\hline Interest in psychiatry & $5.7(1.8)$ & $6.1(2.0)$ & 1.6133 & 0.1077 \\
Knowledge of psychiatry & $3.5(1.6)$ & $6.0(1.3)$ & 15.4053 & 0.0001 \\
Psychiatry as a career & $3.9(2.0)$ & $4.8(2.2)$ & 3.3804 & 0.0008 \\
\hline
\end{tabular}


These were, 'I feel uncomfortable with mentally ill patients'; 'Teaching at my medical school is interesting and of good quality'; and, 'Although I am interested in psychiatry, no effort was made to encourage my becoming a psychiatrist at my medical school'. Items that assessed the overall merits of psychiatry and the efficacy of psychiatry were all favourably rated. Eighty-seven percent at baseline and $91 \%$ at follow-up agreed that, 'Psychiatry is a rapidly expanding frontier of medicine' and $84 \%$ at baseline and $81 \%$ at follow-up disagreed with the statement, 'Psychiatry is unscientific and imprecise'.

With one exception, the items that measured the role, definition and functioning of psychiatrists were all positively rated at baseline, with little capacity for significant improvement at follow-up. One item, 'Among mental health professionals, psychiatrists have the most authority and influence' showed a more divergent viewpoint. Agreement at baseline was $59 \%$, increasing to $68 \%$ at follow-up, however, this was not significant.

Students' were positive about the teaching of psychiatry during the rotation. Seventy-five percent agreed at baseline that teaching was of a good quality and this increased significantly to $93 \%$ at follow-up, McNemars p = 0.001 . Approximately $90 \%$ reported that residents, registrars and consultants they met during the rotation were good role models. There was significant improvement in students views on the level of encouragement to pursue psychiatry as a career, $60 \%$ disagreed at baseline with the statement, 'Although I am interested in psychiatry, no effort was made to encourage my becoming a psychiatrist at my medical school' compared with $77 \%$ at follow-up, McNemars $\mathrm{p}=0.001$.

Several of the 'career and personal reward' items showed less positive attitudes, specifically those that assessed how students and others perceive psychiatry as a discipline and career. Fifty-two percent at baseline agreed that psychiatry has a low prestige among the public and there was no significant change in this at follow-up (47\%). Approximately a third of students at baseline agreed that their family and friends would discourage them from a career in psychiatry and there was no change in this at follow-up. There was only a $22 \%$ agreement with, 'Psychiatry has a high status among other medical disciplines' dropping to $17 \%$ at follow-up, but the difference was not significant.

The percentage agreement/disagreement relating to each item and McNemars test are shown in Table 2 below.

\section{Mental illness stigma}

The baseline mean total score for the MICA was 48.2 (sd 8.3) and the follow-up mean total score was 43.5 (sd 7.5). An unpaired t-test found that this was a significant change, $\mathrm{t}(310)=15.4053, \mathrm{p}=0.0001$ indicating an overall improvement in attitudes towards psychiatry and mental illness stigma post clerkship. The baseline mean score for male students was 49.4 (sd 9.1) and 47.2 (sd 7.4) for females. A Mann-Whitney test found no significant differences between males and females at baseline $(\mathrm{p}=0.068)$. However, at follow-up, the mean score for males was 42.0 (sd 6.0), and 44.8 (sd 8.4) for females, Mann-Whitney ( $\mathrm{p}=0.015)$.

The median scores and level of agreement/disagreement for each MICA item are shown in Table 3. Baseline and follow-up comparison of each MICA item was undertaken using Wilcoxon signed rank tests. Five items showed a significant change post clerkship. Two of these, 'I feel as comfortable talking to a person with a mental illness as I do those with physical illness'; and 'It is important that any doctor supporting a person with a mental illness also assesses their physical health' showed a significant improvement in attitudes post clerkship. Three showed a more negative attitude post clerkship. These were, 'People with a severe mental illness can never recover enough to have a good quality of life'; 'Psychiatry is just as scientific as other field of medicine'; and 'The public does not need to be protected from people with a severe mental illness'. Refer to Table 3 for details.

\section{Discussion}

This study explored the impact of an 8 week psychiatry clerkship on medical students' attitudes towards psychiatry and mental illness stigma. Several different measures assessed interest and knowledge of psychiatry; attitudes towards psychiatry; and perceptions of stigma, both towards mental illness, people with mental illness, the discipline of psychiatry, and psychiatry as a career.

Knowledge and interest in psychiatry were poorly rated at the beginning of the clerkship. At the end of the clerkship there was no significant change in the level of interest in psychiatry, however, there was a significant improvement in students' knowledge, which indicates that despite low interest in psychiatry, the teaching of the clerkship which was highly rated, resulted in an increase in knowledge.

Attitudes towards psychiatry measured using the Balon questionnaire showed that a number of items were positively rated at baseline, leaving little capacity for significant improvements at follow-up. Similar findings have been reported in other studies [29-32]. In particular, attitudes towards mentally ill patients improved significantly post clerkship and there was a correlation between similarly worded items on the Balon and MICA questionnaires, demonstrating a level of internal consistency between the two instruments. Improvements in attitudes towards patients post clerkship have been found in other studies [33,34] supporting the contact theory which proposes that contact with people with mental illness improves attitudes and acceptance towards mental illness [35]. There was also agreement between 
Table 2 Balon attitudes towards psychiatry - baseline and follow-up agreement, and significance

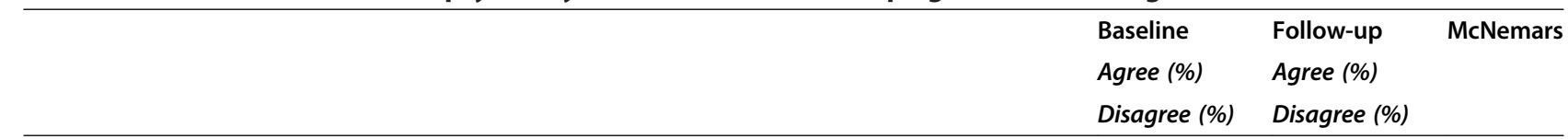

\section{Overall merits of psychiatry}

1. Psychiatric research has made good strides in advancing care of the major mental disorders

2. Psychiatry is a rapidly expanding frontier of medicine

3. Psychiatry is unscientific and imprecise

\section{Efficacy}

4. If someone in my family was very emotionally upset and the situation did not seem to be improving, I would recommend a psychiatric consultation

5. Psychiatric consultation for medical or surgical patients is often helpful

6. Psychiatric treatment is helpful to most people who receive it

\section{Role, definition and functioning of Psychiatrists}

7. Psychiatry is not a genuine and valid branch of medicine

8. Most psychiatrists are clear, logical thinkers

9. With few exceptions, clinical psychologists and social workers are just as

qualified as psychiatrists to diagnose and treat emotionally disturbed persons

10. Among mental health professionals, psychiatrists have the most authority and influence

11. Psychiatrists are too frequently apologetic when teaching psychiatry

12. Psychiatry is too 'biologically' minded and not attentive enough to the patient's personal life and psychological problems

13. Psychiatry is too analytical, theoretical, and psychodynamic, and not attentive enough to patient's physiology

\section{Possible abuse and social criticism}

14. Psychiatrists frequently abuse their legal power to hospitalise patients against their will

15. On average, psychiatrists make as much money as most other doctors

\section{Career and personal reward}

16. Psychiatry has a low prestige among the general public

17. Psychiatry has a high status among other medical disciplines
94

6 
Table 2 Balon attitudes towards psychiatry - baseline and follow-up agreement, and significance (Continued)

\begin{tabular}{|c|c|c|c|}
\hline \multirow[t]{2}{*}{ 19. Psychiatry is a discipline filled with international medical graduates whose skills are of low quality } & 5 & 9 & NS \\
\hline & 95 & 91 & \\
\hline \multirow[t]{2}{*}{ 20. My family would discourage me from entering psychiatry } & 32 & 37 & NS \\
\hline & 68 & 63 & \\
\hline \multirow[t]{2}{*}{ 21. Friends and fellow students would discourage me from entering psychiatry } & 28 & 35 & NS \\
\hline & 72 & 65 & \\
\hline \multirow{2}{*}{$\begin{array}{l}\text { 22. If a student expresses interest in psychiatry, he or she risks being associated with a group } \\
\text { of other would-be psychiatrists who are often seen by others as odd, peculiar or neurotic }\end{array}$} & 30 & 30 & NS \\
\hline & 70 & 70 & \\
\hline \multirow[t]{2}{*}{ 23. I feel uncomfortable with mentally ill patients } & 44 & 16 & 0.001 \\
\hline & 56 & 84 & \\
\hline \multicolumn{4}{|l|}{ Specific medical school factors } \\
\hline \multirow[t]{2}{*}{ 24. Teaching of psychiatry at my medical school is interesting and of good quality } & 75 & 93 & 0.001 \\
\hline & 25 & 7 & \\
\hline \multirow[t]{2}{*}{ 25. During my psychiatry rotation, psychiatry residents were good role models } & N/A & 89 & N/A \\
\hline & N/A & 11 & \\
\hline \multirow[t]{2}{*}{ 26. Attending psychiatrists during my psychiatry rotation were good role models } & N/A & 92 & N/A \\
\hline & N/A & 8 & \\
\hline \multirow[t]{2}{*}{ 27. Most psychiatrists at my medical school are clear, logical thinkers } & 93 & 98 & NS \\
\hline & 7 & 2 & \\
\hline \multirow[t]{2}{*}{ 28. Most non-psychiatry staff at my medical school are respectful of psychiatry } & 80 & 85 & NS \\
\hline & 20 & 15 & \\
\hline \multirow{2}{*}{$\begin{array}{l}\text { 29. Although I am interested in psychiatry, no effort was made to encourage my } \\
\text { becoming a psychiatrist at my medical school }\end{array}$} & 40 & 23 & 0.001 \\
\hline & 60 & 77 & \\
\hline
\end{tabular}

instruments regarding the scientific basis of psychiatry, which was positively rated on both the Balon and MICA, however, the MICA detected a small but significant negative change in this post clerkship.

The baseline and follow-up means for the MICA were close to the neutral value, (48.2 and 43.5 respectively). Despite a significant improvement at follow-up, this shows only weak evidence that the clerkship decreased stigma towards mental illness. The items regarding recovery of people with mental illness and the protection of the public from people with mental illness were more negatively rated post clerkship, and this has also been observed in other studies $[19,36]$. This could reflect the clerkship structure which exposes students to patients with more severe symptoms in acute public inpatient settings, where recovery is not captured or witnessed over the clerkship duration. The post clerkship improvement in students feeling comfortable talking to people with mental illness may be due to psychiatric history taking and assessment skills learned during the clerkship which resulted in increased confidence in interviewing and assessing patients. However, despite this improvement, the disturbed behaviours of patients observed in an acute setting may be interpreted by students as dangerous and could account for the view that the public need to be protected. Changes to the current clerkship structure to provide opportunities for students to work with patients in outpatient and community settings may provide a more realistic view of mental illness enabling students to see positive aspects of treatment and management.

The clerkship, which includes ward work with patient contact, and the weekly tutorial sessions decreased students' perceptions of stigma to some extent, however, there is room for improvement. Addressing stigma through educational interventions is essential for psychiatry to overcome its negative status among students [23], but evidence of the effectiveness of anti-stigma training is mixed. Friedrich and colleagues found that an educational package of lectures, personal testimonies and role play activities improved short term knowledge, attitudes and behaviour, but these effects were not maintained over time [37]. A similar training package found improvements in knowledge, but not in attitudes and behaviour [38]. In order to maintain the positive benefits of anti-stigma training over a longer period of time, these strategies need to be embedded and integrated throughout the curriculum.

It was encouraging that the quality of the psychiatry teaching during the clerkship was highly rated and psychiatrists regarded as good role models. There was a significant increase in the consideration of psychiatry as a 
Table 3 MICA $^{1}$ baseline and follow-up median disagreement and significance

\begin{tabular}{|c|c|c|c|c|c|}
\hline & $\begin{array}{l}\text { Baseline } \\
\text { (Median) }\end{array}$ & $\begin{array}{l}\text { Follow-up } \\
\text { (Median) }\end{array}$ & $\begin{array}{l}\text { Baseline (\%) } \\
\text { SA; A; SWA; } \\
\text { SWD; D; SD }\end{array}$ & $\begin{array}{l}\text { Follow-up (\%) } \\
\text { SA; A; SWA; } \\
\text { SWD; D; SD }\end{array}$ & Wilcoxon \\
\hline \multirow{2}{*}{$\begin{array}{l}\text { Q1. I just learn about psychiatry because it's in the exam } \\
\text { and would not bother reading additional material on it }\end{array}$} & \multirow[t]{2}{*}{4} & \multirow[t]{2}{*}{4} & $1 ; 2.5 ; 30$ & $2 ; 7.5 ; 17 ;$ & \multirow[t]{2}{*}{ NS } \\
\hline & & & $24 ; 32 ; 10.5$ & $38.5 ; 24 ; 11$ & \\
\hline \multirow{2}{*}{$\begin{array}{l}\text { Q2. People with a severe mental illness can never recover } \\
\text { enough to have a good quality of life }\end{array}$} & \multirow[t]{2}{*}{5} & \multirow[t]{2}{*}{4.5} & $1 ; 3 ; 5$ & $3 ; 6.5 ; 11 ;$ & \multirow[t]{2}{*}{$0.001^{* *}$} \\
\hline & & & $26.5 ; 40.5 ; 24$ & $29 ; 38 ; 12.5$ & \\
\hline \multirow[t]{2}{*}{ Q3. Psychiatry is just as scientific as other field of medicine } & \multirow[t]{2}{*}{3} & \multirow[t]{2}{*}{3} & $6 ; 42 ; 35$ & $7 ; 35.5 ; 27$ & \multirow[t]{2}{*}{$0.046^{* *}$} \\
\hline & & & $13 ; 3 ; 1$ & $21 ; 8.5 ; 1$ & \\
\hline \multirow{2}{*}{$\begin{array}{l}\text { Q4. If I had a mental illness I would never admit this to any } \\
\text { of my friends for fear of being treated differently }\end{array}$} & \multirow[t]{2}{*}{3} & \multirow[t]{2}{*}{4} & $4 ; 13 ; 39 ;$ & $2.5 ; 9 ; 32 ;$ & \multirow[t]{2}{*}{ NS } \\
\hline & & & $18 ; 20 ; 6$ & $28.5 ; 23 ; 5$ & \\
\hline \multirow[t]{2}{*}{ Q5. People with a severe mental illness are dangerous more often than not } & \multirow[t]{2}{*}{5} & \multirow[t]{2}{*}{5} & $0 ; 4.5 ; 15$ & $0 ; 6.0 ; 14.5$ & \multirow[t]{2}{*}{ NS } \\
\hline & & & $29 ; 40 ; 11.5$ & $29 ; 41 ; 9.5$ & \\
\hline \multirow{2}{*}{$\begin{array}{l}\text { Q6. Psychiatrists know more about the lives of people } \\
\text { treated for a mental illness than do family members of friends }\end{array}$} & \multirow[t]{2}{*}{3} & \multirow[t]{2}{*}{3} & $2 ; 16 ; 44.5 ;$ & $4.5 ; 15 ; 34 ;$ & \multirow[t]{2}{*}{ NS } \\
\hline & & & $24.5 ; 11 ; 2$ & $28 ; 17 ; 1.5$ & \\
\hline \multirow{2}{*}{$\begin{array}{l}\text { Q7. If I had a mental illness I would never admit this to any } \\
\text { of my colleagues for fear of being treated differently }\end{array}$} & \multirow[t]{2}{*}{3} & \multirow[t]{2}{*}{3} & $8 ; 23 ; 42 ;$ & $9.5 ; 20.5 ; 37.5$ & \multirow[t]{2}{*}{ NS } \\
\hline & & & $18 ; 7 ; 2$ & $20 ; 10.5 ; 2$ & \\
\hline \multirow[t]{2}{*}{ Q8. Being a psychiatrist is not like being a real doctor } & \multirow[t]{2}{*}{5} & 5 & $0 ; 2 ; 10 ;$ & $1 ; 1 ; 8.5$ & NS \\
\hline & & & $18 ; 14 ; 28$ & $21 ; 41.5 ; 27$ & \\
\hline Q9.If a psychiatrist asked me to treat people with a mental & 2 & 2 & $36 ; 42 ; 15 ;$ & $39 ; 40.5 ; 11.5$ & NS \\
\hline & & & $2.5 ; 2.5 ; 2$ & $4.5 ; 2 ; 2.5$ & \\
\hline Q10. I feel as comfortable talking to a person with a mental & 4 & 3 & $4.5 ; 18 ; 23 ;$ & $12.5 ; 36 ; 27$ & $0.0001^{*}$ \\
\hline illness as I do those with physical illness & & & $38.5 ; 15 ; 1$ & $19 ; 4.5 ; 1$ & \\
\hline Q11. It is important that any doctor supporting a person with a & 2 & 1 & $31.5 ; 53.5 ; 14$ & $52 ; 40.5 ; 6.5 ;$ & $0.0001^{*}$ \\
\hline & & & $0 ; 1 ; 0$ & $1 ; 0 ; 0$ & \\
\hline Q12. The public does not need to be protected from people & 4 & 4 & $1 ; 11 ; 24.5 ;$ & $2 ; 10 ; 20 ;$ & $0.041^{* *}$ \\
\hline & & & $43 ; 19 ; 12$ & $34 ; 22.5 ; 11.5$ & \\
\hline Q13. If a person with a mental illness complained of physical symptoms, & 5 & 5 & $0 ; 1 ; 7 ;$ & $0 ; 2 ; 6.5$ & NS \\
\hline & & & $33 ; 49 ; 10$ & $34.5 ; 41 ; 16$ & \\
\hline Q14. GP's should not be expected to complete assessment for people & 5 & 5 & $0 ; 2 ; 11 ;$ & $1.5 ; 3 ; 7 ;$ & NS \\
\hline & & & $29 ; 46 ; 12$ & $32.5 ; 42 ; 14$ & \\
\hline Q15. I would use the terms 'crazy', 'nutter', 'mad' etc. to describe & 5 & 5 & $1.5 ; 4.5 ; 11 ;$ & $1.5 ; 7 ; 15.5 ;$ & NS \\
\hline & & & $18 ; 35 ; 30$ & $23 ; 26.5 ; 26.5$ & \\
\hline Q16. If a colleague told me they had a mental illness I would & 2 & 2 & $21 ; 57 ; 18$ & $31.5 ; 48.5 ; 15$ & NS \\
\hline & & & $2 ; 1 ; 1$ & $3.5 ; 1.5 ; 0$ & \\
\hline
\end{tabular}

${ }^{1}$ MICA - Mental Illness Clinicians Attitudes scale SA = strongly agree (1); A = agree (2); SWA = somewhat agree (3); SWD = somewhat disagree (4); $\mathrm{D}=$ disagree (5); $\mathrm{SD}=$ strongly disagree (6).

*significance demonstrates less stigma post clerkship; ${ }^{* *}$ significance demonstrates more stigma post clerkship.

career which resulted in an additional 10 students who were 'definitely considering' psychiatry as a career post clerkship. Evidence of the impact of the clerkship on career preference is mixed, with some studies finding increases in the level of career interest post clerkship [34,39-41] and others finding no differences [32,33,42]. The clerkship structure, length of clerkship and specific cultural factors may account for the differences in career interest found in these studies that have been conducted in medical schools internationally. While attitudes post clerkship have been found to deteriorate over time as students continue with their studies and internship [43], a positive clerkship experience can have an enduring and positive effect if interested students receive ongoing encouragement from consultants, registrars and other academic staff members [44] as they progress through 
their training. This is particularly important as career decisions regarding specialisation in general are often made up to three years after graduation from medical school [25].

In recent decades, lifestyle factors have been more closely considered by medical students and junior doctors when making career decisions. These include maintaining a work-life balance; choosing a career with a family friendly image; having the opportunity to work part-time; and a manageable, controllable and flexible workload $[15,18,20]$. Psychiatry is well placed to provide positive lifestyle factors for its potential professionals [45], yet it remains an unpopular career choice. Negativity expressed towards psychiatry among friends, family, the public and other medical specialists, psychiatry's poor social prestige and lower earning potential found in this, and other studies $[14,20,46,47]$ may explain why some students do not regard psychiatry favorably as a potential career. Stigma on this level may exert a greater influence over career decision making processes and act to negate the more positive aspects that the discipline has to offer.

In order to mitigate these views, a further role of the clerkship could be to identify students who have a particular interest in psychiatry and provide them with support and mentorship to ensure continued interest over the remainder of the medical course and into internship [18]. Enrichment programmes such as Summer Schools, Psychiatry Institutes and electives can play an important part in targeting students interested in psychiatry and provide them with a more in depth educational exposure to the speciality [48-51]. These types of programmes have been successful in enhancing career interest in psychiatry and in psychiatry as a discipline and could be implemented by medical schools more widely. In addition, the encouragement of student led mental health interest groups also have the potential to encourage positive views towards psychiatry among students, destigmatise mental illness and demystify psychiatry [8].

\section{Study strengths and limitations}

While a number of studies have identified stigma as an issue [12,17], our study was strengthened by the use of a relatively new instrument to measure stigma, the MICA. This adds a new dimension to what is known about the role that stigma plays on students attitudes towards psychiatry and to psychiatry as a career choice.

Limitations of the study are that in order to maintain confidentiality it was not possible to match baseline and follow-up responses as identifying information was not provided by respondents. For students', providing identifying information in surveys is perceived negatively as, despite assurances by staff, they are concerned that their responses, in particular negative responses, may influence their assessment results or treatment by clinical and academic staff in some way. It can also impact negatively on the response rate. For these reasons, it was decided not to use a matched design which would have resulted in a more robust study design but compromised response rates and biased responses to some of the items in the questionnaires, particularly those relating to the treatment of patients and quality of teaching. Not all students in the year group participated in the study and it is possible that selection bias towards those students who are more interested in psychiatry may have contributed towards the improvement in attitudes reported in the results.

This 8 week clerkship takes place in the fourth year of a six year medical course and is the first real exposure that students have to the practical aspects of working with patients with mental illness. At the end of the clerkship there were improvements in attitudes and overall perceptions of mental illness stigma, however, while we can conclude that the clerkship may have contributed towards this improvement, we cannot assume that these views will remain constant as students' progress through the course. There is no certainty that the students at follow-up who stated that they were 'definitely considering' psychiatry will go on to pursue it as a career. Longer term follow-up of the same cohort of students will enable attitudes to be tracked over time to determine how to maintain the gains made during the clerkship and develop appropriate teaching resources that will provide opportunities to further improve attitudes and stigma.

The clerkship is comprised of a number of different components including ward work and tutorials. Future research in this area that specifically assesses each component to find out what works best from a student perspective will help psychiatric educators to structure clerkships that address both the required and relevant educational outcomes and maximise opportunities to improve attitudes towards psychiatry, reduce stigma and increase the number of students who are considering psychiatry as a career.

\section{Conclusion}

The discipline of psychiatry must be able to recruit and retain a viable workforce of psychiatrists that will adequately meet the future needs of the profession. This clerkship made a modest impact on students' attitudes to psychiatry, stigma and consideration of psychiatry as a career. The integration of strategies to overcome stigma, both towards people with mental illness and the mental health profession, into pre-clinical teaching may provide students with skills to better prepare them for the negative aspects of the clerkship and could assist in improving attitudes towards psychiatry and encourage more students to consider psychiatry as a career. Finally, psychiatry is an integral part of the practice of medicine and it is important that, regardless of future area of specialisation, all students foster a positive attitude towards mental illness in order to provide holistic treatment for their patients. 


\section{Competing interests}

The authors declare that they have no competing interests.

\section{Authors' contributions}

The study was designed and carried out by $Z \mathrm{~L}$ and AJ. ZL collected and analysed the data. ZL and AJ both worked on drafts and gave approval for the final version of the paper.

\section{Acknowledgement}

The authors would like to thank UWA colleagues and students who participated in the study. This was an unfunded study.

\section{Received: 6 August 2014 Accepted: 12 February 2015 \\ Published online: 07 March 2015}

\section{References}

1. The WHO World Mental Health Survey Consortium. Prevalence, severity, and unmet need for treatment of mental disorders in the World Health Organization World Mental Health Surveys. JAMA. 2004;291(21):2581-90.

2. The ESEMeD /MHEDEA 2000 Investigators. Prevalence of mental disorders in Europe: results from the European study of the epidemiology of mental disorders (ESEMeD) project. Acta Psychiatr Scand. 2004;109(420):21-7.

3. Evans S, Banerjee $S$, Leese M, Huxley P. The impact of mental illness on quality of life: a comparison of severe mental illness, common mental disorder and healthy population samples. Qual Life Res. 2007;16:17-29.

4. Rusch N, Angermeyer M, Corrigan P. Mental illness stigma: concepts, consequences, and initiatives to reduce stigma. Eur Psychiat. 2005;20:529-39.

5. Ferri C, Prince M, Brayne C, Brodaty H, Fratiglioni L, Ganguli M, et al. Global prevalence of dementia: a Delphi consensus study. Lancet. 2005;366:2112-7.

6. Brookmeyer R, Johnson E, Ziegler-Graham K, Arrighic M. Forecasting the global burden of Alzheimer's disease. Alzh Dem. 2007;3:186-91.

7. Lyons Z. Attitudes of medical students towards psychiatry, and to psychiatry as a career: a systematic review. Acad Psychiatry. 2013;37(3):150-7.

8. Farooq K, Lydall G, Malik A, Ndetei D, Bhugra D, ISOSCCIP Group. Why medical students choose psychiatry - a 20 country cross-sectional survey. BMC Med Educ. 2014;14:12.

9. Goldacre M, Fazel S, Smith F, Lambert T. Choice and rejection of psychiatry as a career: surveys of UK medical graduates from 1974 to 2009. Brit J Psychiat. 2013;202:228-34.

10. Katschnig H. Are psychiatrists an endangered species? Observations on internal and external challenges to the profession. World Psychiatry. 2010;9 (1):21-8.

11. Health Workforce Australia 2025. Volume 3 - Medical Specialties. Adelaide, Australia: Health Workforce Australia; 2012

12. Dixon RP, Roberts LM, Lawrie S, Jones LA, Humphreys MS. Medical students' attitudes to psychiatric illness in primary care. Med Educ. 2008:42(11):1080-7.

13. Ay $P$, Save $D$, Fidanoglu $O$. Does stigma concerning mental disorders differ through medical education? A survey among medical students in Istanbul. Soc Psychiatry Psychiatr Epidemiol. 2005;41:63-7.

14. Balon R, Franchini G, Freeman P, Hassenfeld IN, Keshavan MS, Yoder E. Medical students' attitudes and views of psychiatry: 15 years later. Acad Psychiatry. 1999;23(1):30-6.

15. Cutler J, Harding K, Mozian S, Mozian S, Wright L, Pica A, et al. Discrediting the notion "working with 'crazies' will make you 'crazy"': addressing stigma and enhancing empathy in medical student education. Adv in Health Sci Educ. 2009;14:487-502.

16. Feifel D, Yu Moutier C, Swerdlow N. Attitudes toward psychiatry as a prospective career among students entering medical school. Am J Psychiatry. 1999;156:1397-402.

17. Totic S, Stojiljkovic D, Pavlovic Z, Zaric N, Zarkovic B, Malic L, et al. Stigmatization of 'psychiatric label' by medical and non-medical students. Int J Soc Psychiat. 2011;DOI: 10.1177/0020764011408542:1-8

18. Budd S, Kelley R, Day R, Variend H, Dogra N. Student attitudes to psychiatry and their clinical placements. Med Teach. 2011;33:e586-92.

19. Curtis-Barton M, Eagles J. Factors that discourage medical students from pursuing a career in psychiatry. The Psychiatrist. 2011;35:425-9.

20. Cutler J, Alspector S, Harding K, Wright L, Graham M. Medical students' perceptions of psychiatry as a career choice. Acad Psychiatry. 2006;30(2):144-9.
21. Malhi G, Parker G, Parker K, Kirkby K, Boyce P, Yellowlees P, et al. Shrinking away from psychiatry? A survey of Australian medical students' interest in psychiatry. Aust N Z J Psychiatry. 2002:36:416-23.

22. Pessar L, Pristach C, Leonard K. What troubles clerks in psychiatry? a strategy to explore the question. Acad Psychiatry. 2008;32(3):194-8.

23. Roberts $L$, Bandstra B. Addressing stigma to strengthen psychiatric education. Acad Psychiatry. 2012;36(5):347-50.

24. Hoschl C, Van Niekerk J. Recruitment of psychiatrists: the key role of education. In: Gask L, Coskun B, Baron D, editors. Teaching Psychiatry: Putting Theory into Practice. West Sussex U.K: John Wiley \& Sons Ltd; 2011. p. 5-18.

25. Brown T, Addie K, Eagles J. Recruitment into psychiatry: views of consultants in Scotland. The Psychiatrist. 2007;31:411-3.

26. Serby M, Schmeidler J, Smith J. Length of psychiatry clerkships: recent changes and the relationship to recruitment. Acad Psychiatry. 2002;26(2):102-4.

27. Lyons Z. Impact of the psychiatry clerkship on medical student attitudes towards psychiatry, and to psychiatry as a career: a systematic review. Acad Psychiatry. 2014;38:35-42.

28. Kassam A, Glozier N, Leese M, Henderson C, Thornicroft G. Development and responsiveness of a scale to measure clinicians attitudes to people with mental illness (medical student version). Acta Psychiatr Scand. 2010;122:153-61.

29. Failde I, Salazar A, Elorza J, Casais L, Pérez V, Caballero- Martínez L, et al. Spanish medical students' attitudes and views towards mental health and psychiatry: a multicentric cross-sectional study. Acad Psychiatry. 2014;38:332-8

30. Valdivieso S, Sirhan M, Aguirre C, Ivelic JA, Aillach E, Villarroel L. Attitudes of medical students toward psychiatry in a Chilean medical school. Acad Psychiatry. 2014;38:309-11.

31. Galka S, Perkins D, Butler N, Griffith DA, Schmetzer AD, Avirrappattu G, et al. Medical students' attitudes toward mental disorders before and after a psychiatric rotation. Acad Psychiatry. 2005;29(4):357-61.

32. Niedermier J, Bornstein J, Brandemihl A. The junior medical student psychiatry clerkship: curriculum, attitudes, and test performance. Acad Psychiatry. 2006;30(2):136-43.

33. Sajid A, Khan M, Shakir M, Moazam-Zaman R, Ali A. The effect of clinical clerkship on students' attitudes toward psychiatry in Karachi. Pakistan Acad Psychiatry. 2009;33(3):212-4.

34. Holm-Petersen CS, Vinge S, Hansen J, Gyrd-Hansen J. The impact of contact with psychiatry on senior medical students attitudes toward psychiatry. Acta Psychiatr Scand. 2007;116:308-11.

35. Corrigan P, Penn D. Lessons from social psychology on discrediting psychiatric stigma. Am Psychol. 1999;54(3):765-76.

36. Ramamurthy C, Srikumar P, Joshua E, Rasamy G. Impact of psychiatry training on attitdes of undergraduate medical students. Malay J Psychiatry. 2008;21:22-31.

37. Friedrich B, Evans-Lacko S, London J, Rhydderch R, Henderson C, Thornicroft G. Anti-stigma training for medical students: the Education Not Discrimination project. BJP. 2013;202:s89-94.

38. Kassam A, Glozier N, Leese M, Loughran J, Thornicroft G. A controlled trial of mental illness related stigma training for medical students. BMC Med Educ. 2011;11:51.

39. Bulbena A, Pailhez G, Coll J, Balon R. Changes in the attitudes towards psychiatry among Spanish medical students during training in psychiatry. Eur J Psychiat. 2005;19(2):79-87.

40. Lampe L, Coulston C, Walter G, Malhi G. Familiarity breeds respect: attitudes of medical students towards psychiatry following a clinical attachment. Australas Psychiatry. 2010;18(4):348-53.

41. Rodrigo A, Wijesinghe C, Kuruppuarachchi K. Changes in attitudes toward psychiatry with introduction of a new curriculum: experiences of a Sri Lankan medical school. SL J Psychiatry. 2012;3:14-6.

42. Gazdag G, Zsargó E, Vukov P, Ungvari GS, Tolna J. Change of medical student attitudes toward psychiatry: the impact of the psychiatric clerkship. Psychiatr Hung. 2009;24:248-54.

43. Baxter H, Singh S, Standen P, Duggan C. The attitudes of 'tomorrow's doctors' towards mental illness and psychiatry: changes during the final undergraduate year. Med Educ. 2001;35:381-3.

44. Maidment R, Livingston G, Katona C, McParland M, Noble L. Change in attitudes to psychiatry and intention to pursue psychiatry as a career in newly qualified doctors: a follow-up of two cohorts of medical students. Med Teach. 2004;26(6):565-9. 
45. Thomas T. Factors affecting career choice in psychiatry: a survey of RANZCP trainees. Australas Psychiatry. 2008;16:179-82.

46. Malhi G, Coulston C, Parker G, Cashman E, Walter G, Lampe L, et al. Who picks psychiatry? perceptions, preferences and personality of medical students. Aust N Z J Psychiatry. 2011;45:861-70.

47. Xavier M, Almeida J. Impact of clerkship in the attitudes toward psychiatry among Portuguese medical students. BMC Med Educ. 2010;10:56.

48. Andermann L, De Souza C, Lofchy J. The psychiatry institute for medical students: a decade of success. Acad Psychiatry. 2010;34(2):150-3.

49. Lyons Z, Power B, Bilyk N, Lofchy J, Claassen J. Evaluation of the Claassen Institute of Psychiatry for Medical Students. Australas Psychiatry. 2010;18:12-6.

50. Manassis K, Katz M, Lofchy J, Wiesenthal S. Choosing a career in psychiatry: influential factors within a medical school program. Acad Psychiatry. 2006;30(4):325-9.

51. Karukivi M, Saxen U, Haapasalo Pesu K. Improving recruitment into psychiatry: A summer school for medical students combining clinical work and education. Acad Psychiatry. 2014;DOI 10.1007/s40596-014-0043-9.

\section{Submit your next manuscript to BioMed Central and take full advantage of:}

- Convenient online submission

- Thorough peer review

- No space constraints or color figure charges

- Immediate publication on acceptance

- Inclusion in PubMed, CAS, Scopus and Google Scholar

- Research which is freely available for redistribution 